\title{
熱応力下の三次元異方性異種材界面き裂の応力拡大係数解析*
}

\author{
永井政 貴*1, 池田 徹*1, 宮 崎則 幸*2
}

\section{Stress Intensity Factors Analyses of a Three-Dimensional Interface Crack Between Anisotropic Dissimilar Materials Under Thermal Stress}

\author{
Masaki NAGAI, Toru IKEDA*3 and Noriyuki MIYAZAKI \\ ${ }^{* 3}$ Department of Mechanical Engineering and Science, Graduate School of Engineering, Kyoto University, \\ Yoshida-Honmachi, Sakyo-ku, Kyoto-shi, Kyoto, 606-8501 Japan
}

\begin{abstract}
A new numerical method was presented for stress intensity factors (SIFs) analyses of a threedimensional interface crack between dissimilar anisotropic materials subjected to thermal stress. The $M$-integral method was applied to the thermoelastic interfacial crack in three-dimensional anisotropic bimaterials. The moving least square method was used to calculate the value of the $M$ integral. The $M$-integral in conjunction with the moving least square method can calculate the SIFs from only nodal displacements obtained by the finite element analysis. We analyzed the SIFs of external circular interfacial cracks in jointed dissimilar anisotropic solids subjected to thermal load and showed the distributions of SIFs along the crack front. The distribution of stress and the crack opening displacement obtained by the asymptotic solution with the SIFs are compared with those obtained by the FEM with fine mesh. They are almost identical each other.
\end{abstract}

Key Words : Finite Element Method, Stress Intensity Factor, Interfacial Fracture Mechanics, $M-$ integral, Anisotropy, Moving Least Square Method, Thermal Stress

\section{1. 緒 言}

電子デバイスや MEMS (Micro Electro Mechanical Systems) などの微細構造物で, 複合材料や単結晶な どの異方性を有する材料が積層されて使用されるよう になった背景から，異方性異種材間のはく離や破壊が 信頼性上の大きな問題となっている．異方性異種材界 面破壊力学はこのような接合物の破壊防止に大きく寄 与することが期待できる.

異種材界面き裂の応力拡大係数は，異種材界面き裂 の定量的評価をする上でエネルギ一解放率や $J$ 積分と 並んで重要な破壊力学パラメータである. $\mathrm{Hwu}^{(\mathrm{l})}$ は,

Stroh Formalism ${ }^{(2)}$ を用いて, 異方性異種材界面き裂先 端近傍の変位と応力の漸近解を明らかにし，異方性異 種材界面き裂の応力拡大係数を定義した. また，その 応力拡大係数を求めるための数值解析手法としては,

Qian and $\operatorname{Sun}^{(3)}$ が，材料の対称面の一つが，図 1 に示す き裂周りの座標系における $x_{1}-x_{2}$ 面と平行な直交異方 性材料間の異種材界面き裂の応力拡大係数を求める二

\footnotetext{
* 原稿受付 2007 年 8 月 1 日.

*1 正員, 京都大学大学院工学研究科 (306-8501 京都市左京 区吉田本町).

*2 正員, フェロー, 京都大学大学院工学研究科.

E-mail : ikeda@mech.kyoto-u.ac.jp
}

次元解析手法を提案している．著者らは，既報におい て, $\mathrm{Hwu}^{(1)}$ により求められた異方性異種材界面き裂先 端近傍の漸近解を利用して, 重ね合わせの原理に $J$ 積 分や仮想き裂進展法を適用した, Yau and Wang $\mathrm{g}^{(4)}$ $\operatorname{Matos}^{(\mathfrak{)})}$ らの方法を用いることで, 任意の異方性材料 間の異種材界面き裂の応力拡大係数を求める二次元解 析手法(6,7および二次元解析手法(8)を開発した.

本研究では, 上記の三次元解析手法を, 異種材接合 界面で特に大きな問題となる熱応力問題に拡張し, そ の精度について検討した.

\section{2. 異方性異種材界面き裂の応力拡大係数}

図1 で示される異方性異種材界面き裂を考える. Hwuは, 従来の均質体中のき裂と互換性のある異方性異種材界面 き裂の応力拡大係数を, 次のように定義した ${ }^{(1)}$.

$$
\begin{gathered}
\mathbf{K}=\left\{\begin{array}{c}
K_{\mathrm{II}} \\
K_{\mathrm{I}} \\
K_{\mathrm{III}}
\end{array}\right\}=\lim _{r \rightarrow 0} \sqrt{2 \pi r} \Lambda\left\langle\left\langle\left(r / l_{k}\right)^{-i \varepsilon_{\alpha}}\right\rangle\right) \Lambda^{-1}\left\{\begin{array}{c}
\sigma_{12} \\
\sigma_{22} \\
\sigma_{23}
\end{array}\right\} \\
\Lambda=\left[\lambda_{1}, \lambda_{2}, \lambda_{3}\right]
\end{gathered}
$$

ここで, $r$ はき裂先端からの距離, $l_{k}$ は任意の代表長 さであり，〈〈〉は, $\alpha=1,2,3$ なる対角成分をもつ対 
角マトリックスであることを示す. また, $\lambda_{\alpha}$ は, 次式 の固有関係を満たす固有べクトルである.

$$
\left(\mathbf{M}^{*}+e^{2 i \pi \delta} \overline{\mathbf{M}}^{*}\right) \boldsymbol{\lambda}=\mathbf{0}
$$

この式の固有値 $\delta_{\alpha}$ は, 次式のようになる ${ }^{(9)}$.

$$
\begin{gathered}
\delta_{\alpha}=-\frac{1}{2}+i \varepsilon_{\alpha}, \quad \alpha=1,2,3 \\
\varepsilon_{1}=\varepsilon=\frac{1}{2 \pi} \ln \frac{1+\beta}{1-\beta}, \quad \varepsilon_{2}=-\varepsilon, \quad \varepsilon_{3}=0, \\
\beta=\left[-\frac{1}{2} \operatorname{tr}\left(\mathbf{W D}^{-1}\right)^{2}\right]^{1 / 2}
\end{gathered}
$$

また， $\mathbf{M}^{*}$ は, 次のような二つの材料の Barnett-Lothe テンソル $\mathbf{S}_{j}, \mathbf{L}_{j}$ より得られる(10).

$$
\begin{gathered}
\mathbf{M}^{*}=\mathbf{D}-i \mathbf{W} \\
\mathbf{D}=\mathbf{L}_{1}^{-1}+\mathbf{L}_{2}^{-1}, \quad \mathbf{W}=\mathbf{S}_{1} \mathbf{L}_{1}^{-1}-\mathbf{S}_{2} \mathbf{L}_{2}^{-1}
\end{gathered}
$$

一方, エネルギー解放率 $G$ と応力拡大係数 $\mathbf{K}$ の間に は，次のような関係がある(1).

$$
G=\frac{1}{4} \mathbf{K}^{T} \mathbf{E K}, \mathbf{E}=\mathbf{D}+\mathbf{W D}^{-1} \mathbf{W}
$$

このとき，図 1 の $x_{1}$ 軸上でのき裂前方の応力とき裂 開口変位は, 次式のようになる ${ }^{(1)}$.

$$
\begin{gathered}
\left\{\begin{array}{l}
\sigma_{12} \\
\sigma_{22} \\
\sigma_{32}
\end{array}\right\}=\frac{1}{\sqrt{2 \pi r}} \boldsymbol{\Lambda}\left\langle\left\langle\left(r / l_{k}\right)^{i \varepsilon_{\alpha}}\right\rangle\right\rangle \boldsymbol{\Lambda}^{-1} \mathbf{K} \\
\left\{\begin{array}{l}
\Delta u_{1} \\
\Delta u_{2} \\
\Delta u_{3}
\end{array}\right\}=\sqrt{\frac{2 r}{\pi}} \bar{\Lambda}^{-T}\left\langle\left\langle\frac{\left(r / l_{k}\right)^{i \varepsilon_{a}}}{\left(1+2 i \varepsilon_{\alpha}\right) \cosh \left(\pi \varepsilon_{\alpha}\right)}\right\rangle\right\rangle \boldsymbol{\Lambda}^{-1} \mathbf{K}(10)
\end{gathered}
$$

均質体中のき裂の場合，モード II， I，III の応力場は 独立しており, 図 1 におけるき裂前方の $x_{1}$ 軸上の応 力比 $\sigma_{12} / \sigma_{22}, \sigma_{22} / \sigma_{22}$ は常に $K_{\mathrm{II}} / K_{\mathrm{I}}, K_{\mathrm{II}} / K_{\mathrm{I}}$ に一致する. し かしながら，異方性異種材界面き裂の場合，一般的に これらの応力場は連成しており，その比はき裂先端か らの距離 $r$ によって変化する. ただし, 二つの材料の 対称面の一つが，それぞれ $x_{1}-x_{2}$ 面と平行な場合は，

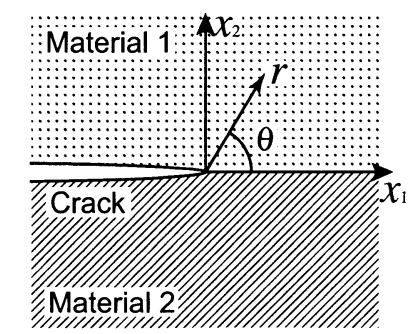

Fig. 1 An interface crack between dissimilar anisotropic media.
モード III が独立成分となり, モード II と I のみが連 成する. 式(9)より, 明らかに $\sigma_{12} / \sigma_{2}, \sigma_{23} / \sigma_{22}$ が $K_{\mathrm{I}} / K_{\mathrm{l}}$, $K_{\mathrm{II}} / K_{\mathrm{I}}$ に一致するのは $r=l_{k}$ のときである. すなわち, $l_{k}$ をある值に選ぶということは, 応力拡大係数 $K_{\mathrm{I}}, K_{\mathrm{I}}$ と $K_{\text {III }}$ r $=l_{k}$ での各応力の比を代表させることを意味 寸る. よって, $l_{k}$ を $l_{k}$ に変化させた場合, 応力拡大係 数の比は次式に従って変化する.

$$
\mathbf{K}^{\prime}=\boldsymbol{\Lambda}\left\langle\left\langle\left(\frac{l_{k}^{\prime}}{l_{k}}\right)^{i \epsilon_{a}}\right\rangle\right\rangle \boldsymbol{\Lambda}^{-1} \mathbf{K}
$$

また, 異方性異種材界面き裂の応力拡大係数を混合 モードの破壊勒性值として利用するためには, 応力拡 大係数が一意的にき裂先端の応力場を規定する必要が ある. このためには， $l_{k}$ が同じ值のときの応力拡大係 数を用いるべきである. 本研究では, これまでの等方 性異種材界面き裂の研究(1)を参考にして, 便宜的に $l_{k}=$ $10 \mu \mathrm{m}$ として計算している.

\section{3. 解析方法}

3.1 移動最小自乗法 本論文では, $M$ 積分を 計算する際に必要となる任意の点でのひずみ・応力值 を, 有限要素法解析結果の節点変位より, 移動最小自 乗法を用いて近似することで得ている. これにより, 入力データの大幅な削減と, 解析の自動化を可能にして いる. 以下に, 移動最小自乗法について簡単に説明する.

任意の点 $\boldsymbol{x}$ での変位 $u^{h}(\boldsymbol{x})$ を, $\mathbf{p}^{T}(\boldsymbol{x})=\{1, x, y, z\}$ を 基底関数として近似的に次式のように表す.

$$
u^{h}(\boldsymbol{x})=\mathbf{p}^{T}(\boldsymbol{x}) \mathbf{a}(\boldsymbol{x})
$$

式(12) で, 未定係数 $\mathbf{a}(\boldsymbol{x})$ は, 次式で定義される重み 付き自乗和 $R(x)$ を最小にするように決定される.

$$
R(\boldsymbol{x})=\sum_{I}^{n} w\left(\boldsymbol{x}-\boldsymbol{x}_{I}\right)\left[\mathbf{p}^{T}\left(\boldsymbol{x}_{\boldsymbol{I}}\right) \mathbf{a}(\boldsymbol{x})-u_{I}\right]^{2}
$$

ここで, $u_{I}$ は, 評価点 $x$ から定めた影響半径の領域内 に分布する節点の変位, $w\left(x-\boldsymbol{x}_{1}\right)$ は点 $x$ の近傍で定義 される重み関数である. 本論文では重み関数には次式 の指数型の関数を用いた.

$$
w(\rho)= \begin{cases}\frac{\exp \left(-(\rho / c)^{2}\right)-\exp \left(-(1 / c)^{2}\right)}{1-\exp \left(-(1 / c)^{2}\right)}, & \text { if } \rho \leq 1 \\ 0, & \text { if } \rho>1\end{cases}
$$

ここで, $\rho=d_{I} / d_{m l}, d_{I}=\left\|x-x_{l}\right\|$ である. $d_{m l}$ は影響半 径であり，本論文では，経験的に評価点から三番目に 近い節点と評価点の距離に，スケーリングファクタを 掛けた值を用いている. このスケーリングファクタに 
は，大体 3.0〜4.5 にとっておけば解析精度が保たれる ことを確認している. また, $c$ は重み関数を制御する 変数で $c=0.50$ とした. 式(13) から未定係数 $\mathbf{a}(\boldsymbol{x})$ を決 定すると, 式(12) は次式のようになる.

$$
u^{h}=\sum_{I}^{n} \sum_{j}^{m} p_{j}(\boldsymbol{x})\left[\mathbf{X}^{-1}(\boldsymbol{x}) \mathbf{Y}(\boldsymbol{x})\right]_{j I} u_{I} \equiv \sum_{I}^{n} \phi_{I}(\boldsymbol{x}) u_{I}
$$

近似関数 $\phi_{I}(x)$ は次式から得られる.

$$
\begin{aligned}
& \phi_{I}(\boldsymbol{x})= \sum_{j}^{m} p_{j}(\boldsymbol{x})\left[\mathbf{X}^{-1}(\boldsymbol{x}) \mathbf{Y}(\boldsymbol{x})\right]_{j I} \\
& \mathbf{X}(\boldsymbol{x})=\sum_{I}^{n} w\left(\boldsymbol{x}-\boldsymbol{x}_{I}\right) \mathbf{p}\left(\boldsymbol{x}_{I}\right) \mathbf{p}^{T}\left(\boldsymbol{x}_{I}\right) \\
& \mathbf{Y}(\boldsymbol{x})=\left[w\left(\boldsymbol{x}-\boldsymbol{x}_{1}\right) \mathbf{p}\left(\boldsymbol{x}_{1}\right), w\left(\boldsymbol{x}-\boldsymbol{x}_{2}\right) \mathbf{p}\left(\boldsymbol{x}_{2}\right),\right. \\
&\left.\ldots, w\left(\boldsymbol{x}-\boldsymbol{x}_{n}\right) \mathbf{p}\left(\boldsymbol{x}_{n}\right)\right]
\end{aligned}
$$

界面に近い評価点の変位場を近似する場合は, 影響半 径内の節点で界面をまたいでいるものを除外して計算 している. こうすることで界面での変位勾配の不連続 を取り扱うことができる.

\section{2 三次元熱弾性問題の $M$ 積分 2 章で述心} たとおり，異方性異種材界面き裂の場合，荷重条件が 単一モードであっても, 応力拡大係数は混合モード状 態となり，モード分離が必要となる. Yau and Wang ${ }^{(4)}$ は, 応力拡大係数の重㸚合わせの原理と $J$ 積分を利用 した, 混合モードき裂のモード分離を行う $M$ 積分を,

異種材界面き裂に適用した。本論文では，この $M$ 積分 を三次元異種材界面き裂の熱弾性問題に適用した. 以下 にその概略を示す.

三次元熱弾性問題の $J$ 積分は次式のように定義され $ろ^{(12)}$.

$$
\begin{aligned}
& J=\int_{\Gamma}\left(W^{e} n_{1}-T_{i} \frac{\partial u_{i}}{\partial x_{1}}\right) d \Gamma \\
& +\iint_{\Omega}\left\{\sigma_{i j} \alpha_{i j} \frac{\partial \vartheta}{\partial x_{1}}-\frac{\partial}{\partial x_{3}}\left(\sigma_{i 3} \frac{\partial u_{i}}{\partial x_{1}}\right)\right\} d \Omega
\end{aligned}
$$

ここで，「はき裂前縁に垂直な平面上でき裂先端を囲 む経路， $\Omega$ は上記平面上で $\Gamma$ で囲まれる面領域を示 す.また, W は弾性ひずみエネルギ一密度, $n_{1}$ は $\Gamma$

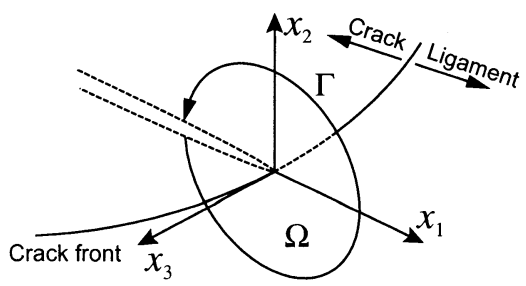

Fig. 2 Schematic of the $J$-integral in a three-dimensional body.
上での法線ベクトルの $x_{1}$ 方向成分, $T_{i}$ は $\Gamma$ 上に作用 する表面力ベクトル， $u_{i}, \sigma_{i j}$ はそれぞれ変位, 応力. $\alpha_{i j}$ けはそれぞれ線膨張係数, 温度を示寸.

解析対象に, あらかじめ変位, 応力, 応力拡大係数 が既知な平面ひずみ状態にある解を重ね合わせること を考える. 解析対象を状態(1), 重ね合わせる既知の 解を状態 (2), 両者を重ね合わせた状態を(1+2) とする と, 状態 $(1+2)$ の任意の点の変位, 応力, 応力拡大係 数に次のような重ね合わせの原理が成り立つ.

$$
\left\{\begin{array}{l}
u_{i}^{(1+2)}=u_{i}^{(1)}+u_{i}^{(2)} \\
\sigma_{i j}^{(1+2)}=\sigma_{i j}^{(1)}+\sigma_{i j}^{(2)} \\
\mathbf{K}^{(1+2)}=\mathbf{K}^{(1)}+\mathbf{K}^{(2)}
\end{array}\right.
$$

したがって, 式(8)より状態(1+2)のエネルギー解放率 は次のようになる.

$$
\begin{aligned}
J^{(1+2)} & =\frac{1}{4}\left\{\mathbf{K}^{(1)}+\mathbf{K}^{(2)}\right\}^{T} \mathbf{E}\left\{\mathbf{K}^{(1)}+\mathbf{K}^{(2)}\right\} \\
& =J^{(1)}+J^{(2)}+\frac{1}{4}\left\{\mathbf{K}^{(1) T} \mathbf{E} \mathbf{K}^{(2)}+\mathbf{K}^{(2) T} \mathbf{E} \mathbf{K}^{(1)}\right\}
\end{aligned}
$$

これを変形すると次式が得られる.

$$
\frac{1}{4}\left\{\mathbf{K}^{(1) T} \mathbf{E} \mathbf{K}^{(2)}+\mathbf{K}^{(2) T} \mathbf{E K}^{(1)}\right\}=J^{(1+2)}-J^{(1)}-J^{(2)}=M
$$

ここで,

$$
\begin{aligned}
M & =\int_{\Gamma}\left\{\sigma_{i j}^{(1)} \varepsilon_{i j}^{(2)} n_{1}-\left(T_{i}^{(1)} \frac{\partial u_{i}^{(2)}}{\partial x_{1}}+T_{i}^{(2)} \frac{\partial u_{i}^{(1)}}{\partial x_{1}}\right)\right\} d \Gamma \\
& +\iint_{\Omega}\left\{\sigma_{i j}^{(2)} \alpha_{i j} \frac{\partial \vartheta^{(1)}}{\partial x_{1}}-\left(\frac{\partial \sigma_{i 3}^{(1)}}{\partial x_{3}} \frac{\partial u_{i}^{(2)}}{\partial x_{1}}+\sigma_{i 3}^{(2)} \frac{\partial^{2} u_{i}^{(1)}}{\partial x_{3} \partial x_{1}}\right)\right\} d \Omega
\end{aligned}
$$

式(22)において，左辺の $\mathbf{E}, \mathbf{K}^{(2)}$ は既知であるので， 3 つの独立した既知の解を解析対象に重ね合わせること によって, 式(23)の $\boldsymbol{M}$ 積分值より $\mathbf{K}^{(1)}$ を求めること ができる. 例えば，重ね合わせる既知の解として，異 方性異種材界面き裂の漸近解を用いる場合を考える. この漸近解について, 既知の解 $(a)\left[K_{\mathrm{II}}^{(2)}=1, K_{\mathrm{I}}^{(2)}=\right.$ $\left.0, K_{\mathrm{III}}^{(2)}=0\right]$ ], (b) [ $\left.K_{\mathrm{II}}^{(2)}=0, K_{\mathrm{I}}^{(2)}=1, K_{\mathrm{III}}^{(2)}=0\right],(c)\left[K_{\mathrm{II}}^{(2)}=0\right.$, $K_{\mathrm{I}}^{(2)}=0, K_{\mathrm{III}}^{(2)}=1 \mathrm{j}$ の場合を重ね合わせると, 式(22)より, 次式の連立 1 次方程式を求めることができる.

$$
\left[\begin{array}{lll}
E_{11} & E_{12} & E_{13} \\
E_{21} & E_{22} & E_{23} \\
E_{31} & E_{32} & E_{33}
\end{array}\right]\left\{\begin{array}{l}
K_{\mathrm{II}}^{(1)} \\
K_{1}^{(1)} \\
K_{\mathrm{III}}^{(1)}
\end{array}\right\}=2\left\{\begin{array}{l}
M_{(\mathrm{a})} \\
M_{(\mathrm{b})} \\
M_{(\mathrm{c})}
\end{array}\right\}
$$

これを解くことで, 解析対象の応力拡大係数 $K_{\mathrm{II}}^{(1)}$, $K_{\mathrm{I}}^{(1)}, K_{\mathrm{III}}^{(1)}$ が得られる. 実際の解析では, 桁落ちが生 じないように, 適当な大きさの応力拡大係数の值を重 ね合わせる漸近解に用いる. 


\section{4. 解析結果}

3 章で述べた解析手法の有效性を検討するため, 図 3 に示すような, 半径 $a$ の円形領域のみを接合した異 種材接合体について, 全体を $20^{\circ} \mathrm{C}$ 一様冷却した場合

(Sample 1) と， $X$ 軸方向に- $0.1^{\circ} \mathrm{C} / \mathrm{mm}$ の一样温度勾 配をもたせた場合（Sample 2) のき裂の応力拡大係数 を解析した. 材料の組合せは, 表 1 に示寸ような材料 定数昼, 13, 14)を使い，表 2 の組合せについて解析を行っ た. Aragonite と Topaz は直交異方性材料, GSO は単 斜晶材料である. 有限要素法解析は, 対称条件を考慮 した $1 / 2$ モデルで $a=10 \mathrm{~mm}$ とし, 20 節点アイソパラ メトリック要素を用いて, 沉用コードMarcで行った. 解の収束性を確認するため表 3 に示寸ような有限要素 分割の精粗の異なる 3 種類のメッシュを使用した.

以上のような条件で，まず Mesh 1 を用いて， $M$ 積 分の経路独立性を調べた. 図 3 に示寸き裂前縁 $\varphi=$ $22.5^{\circ}$ の位置において, 境界条件を Sample 1, 材料の 組合せを Case 2 としたときの, 解析結果の積分経路 半径による変化を図 4 に示した. 図 4 の結果から, 積 分経路半径 $r=1.5 \mathrm{~mm}$ 以上では, 経路独立性が成立し ていることがわかる.この半径は, き裂先端周りの最 小有限要素サイズがリガメント半径 $a$ に対して $1 / 20$ である Mesh 1 では, 最小要素サイズの 3 倍以上の距 離に対応する.

つぎに, $\varphi=22.5^{\circ}, 90^{\circ}, 157.5^{\circ}$ の各点において, 各要 素分割により求めたエネルギ一解放率と応力拡大係数 を表4〜7に示寸.これより, どのケースについても， 要素分割が細かくなるにつれて, 值が収束していって

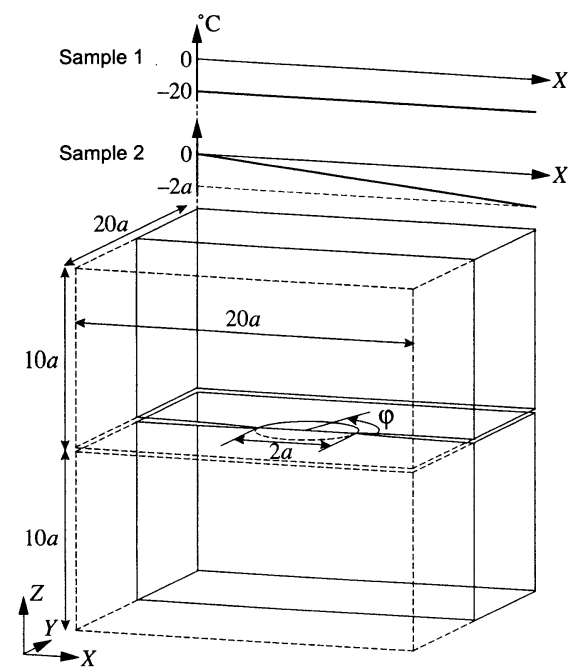

Fig. 3 An external circular interface crack between dissimilar anisotropic materials subjected to thermal stress.
Table 1 Elastic stiffness $C_{i j}(\mathrm{GPa})$ and CTE $\alpha_{i j}\left(10^{-6} \%^{\circ} \mathrm{C}\right)$

\begin{tabular}{cccc}
\hline $\begin{array}{c}\text { Material } \\
\text { properties }\end{array}$ & $\begin{array}{c}\text { Aragonite } \\
\text { (Orthotropic) }\end{array}$ & $\begin{array}{c}\text { Topaz } \\
\text { (Orthotropic) }\end{array}$ & $\begin{array}{c}\text { GSO } \\
\text { (Monoclinic) }\end{array}$ \\
\hline$C_{11}$ & 160 & 281 & 223 \\
$C_{12}$ & 36.6 & 126 & 108 \\
$C_{13}$ & 1.97 & 84.6 & 98.5 \\
$C_{15}$ & 0 & 0 & 84 \\
$C_{22}$ & 87 & 349 & 150 \\
$C_{23}$ & 15.9 & 88.2 & 102 \\
$C_{25}$ & 0 & 0 & 33.3 \\
$C_{33}$ & 85 & 295 & 251 \\
$C_{35}$ & 0 & 0 & -6 \\
$C_{44}$ & 41.3 & 108 & 78.8 \\
$C_{46}$ & 0 & 0 & 6.6 \\
$C_{55}$ & 25.6 & 133 & 68.8 \\
$C_{66}---12.7$ & 131 & 82.7 \\
\hline$\alpha_{11}$ & 35.0 & 5.9 & 4.4 \\
$\alpha_{22}$ & 17.0 & 4.8 & 14.0 \\
$\alpha_{33}$ & 10.0 & 4.4 & 6.8 \\
$\alpha_{31}$ & - & - & -1.4 \\
\hline
\end{tabular}

Table 2 Material combinations for thermoelastic analyses.

\begin{tabular}{ccc}
\hline Combinations & Material 1 & Material 2 \\
\hline Case 1 & Aragonite & Topaz \\
Case 2 & Aragonite & GSO \\
\hline
\end{tabular}

Table 3 Finite Element meshes for thermoelastic analyses.

\begin{tabular}{cccc}
\hline Mesh & $\begin{array}{c}\text { Number of } \\
\text { nodes }\end{array}$ & $\begin{array}{c}\text { Number of } \\
\text { elements }\end{array}$ & $m / a$ \\
\hline Mesh 1 & 246,487 & 58,432 & 0.05 \\
Mesh 2 & 474,851 & 114,000 & 0.025 \\
Mesh 3 & 685,529 & 165,840 & 0.0125 \\
\hline
\end{tabular}

$\mathrm{m}$ : size of the smallest element around a crack tip.

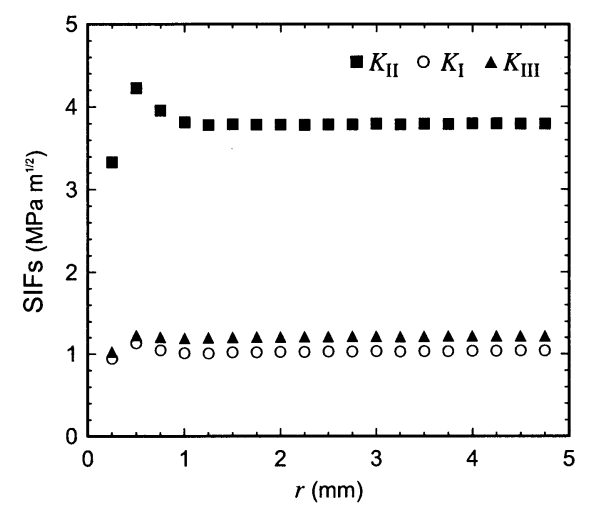

Fig. 4 The relationship between the SIFs and the path radius.

いるのがわかる.これらの結果をもとに, Mesh 1 を 用いて, き裂前縁に沿った応力拡大係数の解析結果を 図 5〜8 に示す。これより, 熱応力問題の特徵である せん断モード（モード II, III）支配の傾向が見られ， 異方性の影響により，き裂先端での性質がき裂前縁の 位置によって大きく変化していることがわかった.

また, Mesh 1 を用いて本手法により得られた忘力 拡大係数を，式(9)，(10)のき裂先端近傍の応力とき 
裂開口変位 (Crack Opening Displacement: COD) の漸 近解に代入し，その分布を求めた. これを Mesh 3 を 用いて有限要素法により直接得られた応力值・開口変 位の分布と比較したものを, 図9〜12 に示した. なお, Sample 1 に関しては Case 2 の結果を, Sample 2 に関 しては Case 1 の結果を示している. 図 9,10において は, 図 3 におけるき裂前縁 $\varphi=22.5^{\circ}, 90^{\circ}, 157.5^{\circ}$ の 3 点 でのき裂前方界面上の応力を示した．また，参考のた

Table 4Calculated stress intensity factors (Case 1 - Sample 1).

\begin{tabular}{cccccc}
\hline$\varphi$ & Mesh & $G$ & $K_{\mathrm{II}}$ & $K_{\mathrm{I}}$ & $K_{\mathrm{II}}$ \\
\cline { 3 - 6 } degrees & & $10^{2} \mathrm{~J} / \mathrm{m}^{2}$ & \multicolumn{3}{c}{$\mathrm{MPa} \mathrm{m}^{12}, l_{k}=10 \mu \mathrm{m}$} \\
\hline \multirow{2}{*}{22.5} & Mesh 1 & 1.40 & 4.31 & 1.35 & 0.97 \\
& Mesh 2 & 1.39 & 4.31 & 1.36 & 0.97 \\
& Mesh 3 & 1.39 & 4.33 & 1.35 & 0.97 \\
\hline \multirow{2}{*}{90.0} & Mesh 1 & 0.37 & 2.07 & 0.88 & 0.01 \\
& Mesh 2 & 0.36 & 2.08 & 0.90 & -0.01 \\
& Mesh 3 & 0.37 & 2.09 & 0.91 & -0.01 \\
\hline \multirow{2}{*}{157.5} & Mesh 1 & 1.40 & 4.31 & 1.35 & -0.97 \\
& Mesh 2 & 1.39 & 4.31 & 1.36 & -0.97 \\
& Mesh 3 & 1.39 & 4.33 & 1.35 & -0.97 \\
\hline
\end{tabular}

Table 5 Calculated stress intensity factors (Case 2 - Sample 1).

\begin{tabular}{cccccc}
\hline $\begin{array}{c}\varphi \\
\varphi\end{array}$ & Mesh & $G$ & $K_{\mathrm{II}}$ & $K_{\mathrm{I}}$ & $K_{\mathrm{II}}$ \\
\cline { 3 - 6 } degrees & & $10^{2} \mathrm{~J} / \mathrm{m}^{2}$ & \multicolumn{3}{c}{$\mathrm{MPa} \mathrm{m}^{12}, l_{k}=10 \mu \mathrm{m}$} \\
\hline \multirow{2}{*}{22.5} & Mesh 1 & 1.26 & 3.79 & 1.03 & 1.21 \\
& Mesh 2 & 1.25 & 3.78 & 1.02 & 1.20 \\
& Mesh 3 & 1.26 & 3.79 & 1.02 & 1.20 \\
\hline \multirow{2}{*}{90.0} & Mesh 1 & 0.07 & 0.73 & 0.22 & -0.02 \\
& Mesh 2 & 0.06 & 0.75 & 0.24 & -0.03 \\
& Mesh 3 & 0.06 & 0.75 & 0.24 & -0.03 \\
\hline \multirow{3}{*}{157.5} & Mesh 1 & 1.23 & 3.62 & 0.97 & -1.33 \\
& Mesh 2 & 1.22 & 3.64 & 0.98 & -1.33 \\
& Mesh 3 & 1.22 & 3.65 & 0.97 & -1.33 \\
\hline
\end{tabular}

Table 6 Calculated stress intensity factors (Case 1 - Sample 2).

\begin{tabular}{|c|c|c|c|c|c|}
\hline \multirow{2}{*}{$\begin{array}{c}\varphi \\
\text { degrees } \\
\end{array}$} & \multirow[t]{2}{*}{ Mesh } & $G$ & $K_{\mathrm{II}}$ & $K_{\mathrm{I}}$ & $K_{\text {III }}$ \\
\hline & & $\mathrm{J} / \mathrm{m}^{2}$ & \multicolumn{3}{|c|}{$\mathrm{MPa} \mathrm{m}^{12}, l_{k}=10 \mu \mathrm{m}$} \\
\hline \multirow{3}{*}{22.5} & Mesh 1 & 38.7 & 2.27 & 0.71 & 0.49 \\
\hline & Mesh 2 & 38.4 & 2.27 & 0.71 & 0.49 \\
\hline & Mesh 3 & 38.4 & 2.28 & 0.71 & 0.49 \\
\hline \multirow{3}{*}{90.0} & Mesh 1 & 9.22 & 1.03 & 0.44 & -0.07 \\
\hline & Mesh 2 & 9.13 & 1.04 & 0.45 & -0.07 \\
\hline & Mesh 3 & 9.17 & 1.05 & 0.46 & -0.07 \\
\hline \multirow{3}{*}{157.5} & Mesh 1 & 31.5 & 2.04 & 0.64 & -0.48 \\
\hline & Mesh 2 & 31.4 & 2.04 & 0.65 & -0.48 \\
\hline & Mesh 3 & 31.4 & 2.05 & 0.64 & -0.48 \\
\hline
\end{tabular}

Table 7 Calculated stress intensity factors (Case 2 - Sample 2).

\begin{tabular}{cccccc}
\hline $\begin{array}{c}\varphi \\
\text { degrees }\end{array}$ & Mesh & $G$ & $K_{\text {II }}$ & $K_{\mathrm{I}}$ & $K_{\text {II }}$ \\
\cline { 3 - 6 } 22.5 & & $\mathrm{~J} / \mathrm{m}^{2}$ & \multicolumn{3}{c}{$\mathrm{MPa} \mathrm{m}^{12}, l_{k}=10 \mu \mathrm{m}$} \\
\hline \multirow{2}{*}{22.5} & Mesh 1 & 34.5 & 1.99 & 0.53 & 0.63 \\
& Mesh 2 & 34.3 & 1.98 & 0.53 & 0.62 \\
& Mesh 3 & 34.4 & 1.99 & 0.53 & 0.62 \\
\hline \multirow{2}{*}{90.0} & Mesh 1 & 1.78 & 0.36 & 0.11 & -0.05 \\
& Mesh 2 & 1.58 & 0.37 & 0.12 & -0.06 \\
& Mesh 3 & 1.53 & 0.38 & 0.12 & -0.06 \\
\hline \multirow{3}{*}{157.5} & Mesh 1 & 28.1 & 1.73 & 0.46 & -0.64 \\
& Mesh 2 & 27.8 & 1.73 & 0.46 & -0.64 \\
& Mesh 3 & 27.8 & 1.73 & 0.46 & -0.64 \\
\hline
\end{tabular}

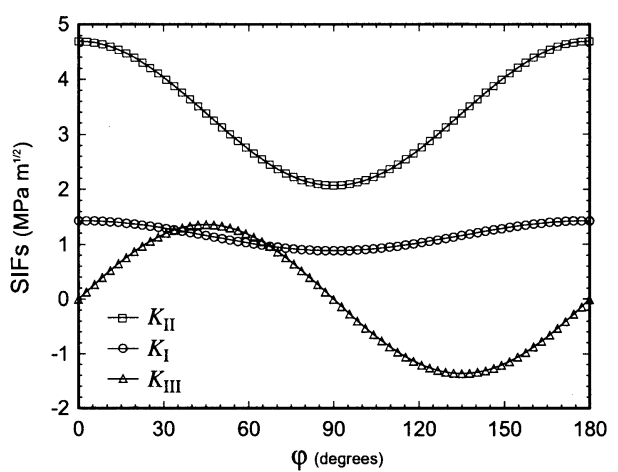

Fig. 5 SIFs distributions along the crack front for Case 1 in Sample 1.

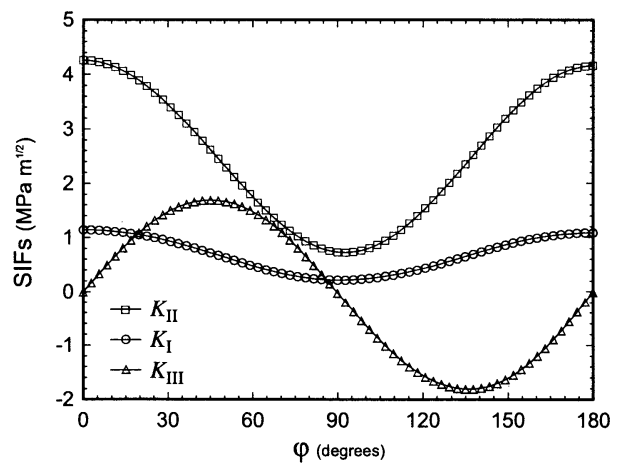

Fig. 6 SIFs distributions along the crack front for Case 2 in Sample 1.

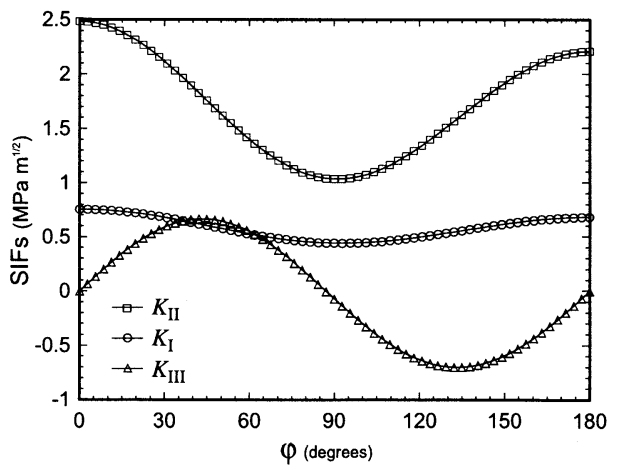

Fig. 7 SIFs distributions along the crack front for Case 1 in Sample 2.

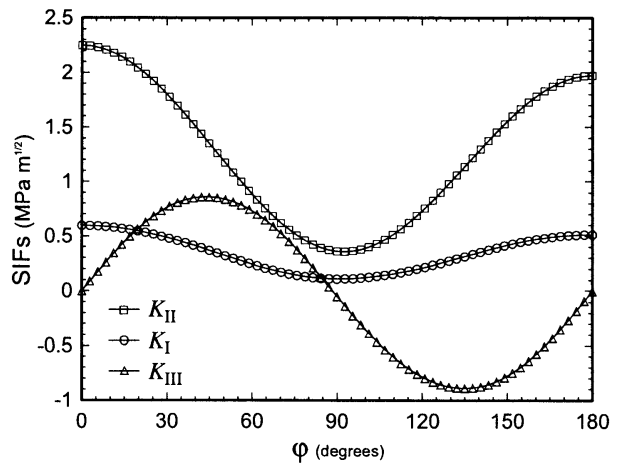

Fig. 8 SIFs distributions along the crack front for Case 2 in Sample 2. 


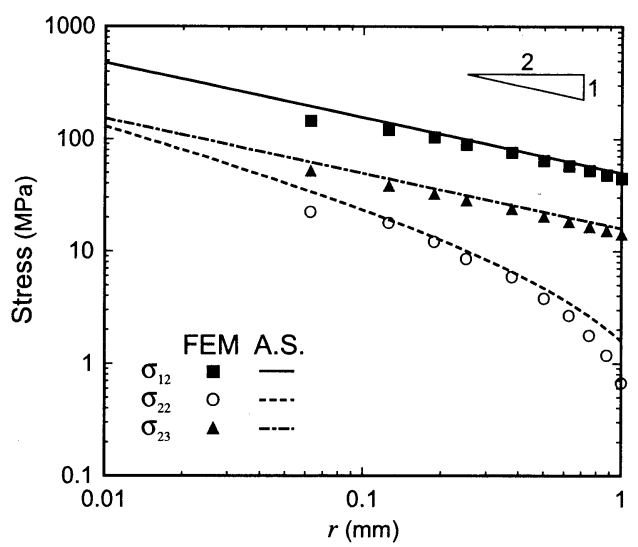

(a) $\varphi=22.5^{\circ}$

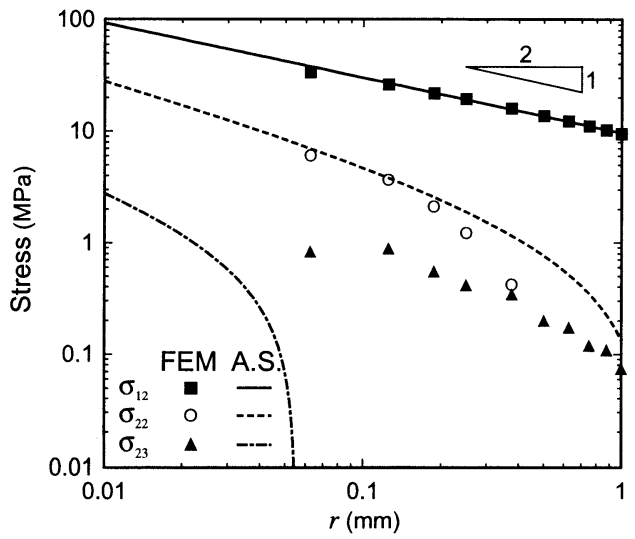

(b) $\varphi=90.0^{\circ}$

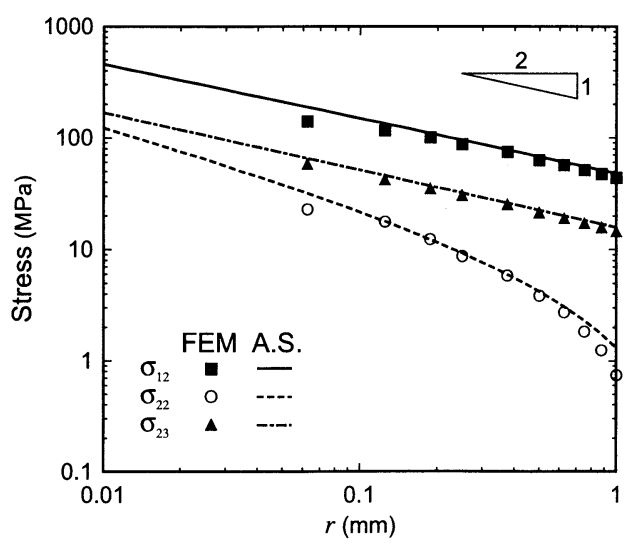

(c) $\varphi=157.5^{\circ}$

Fig. 9 Distributions of stress in the vicinity of an interface crack tip obtained by the asymptotic solution with calculated stress intensity factors and obtained by the FEM directly, for Case 2 in Sample 1 (A.S.: Asymptotic Solution).

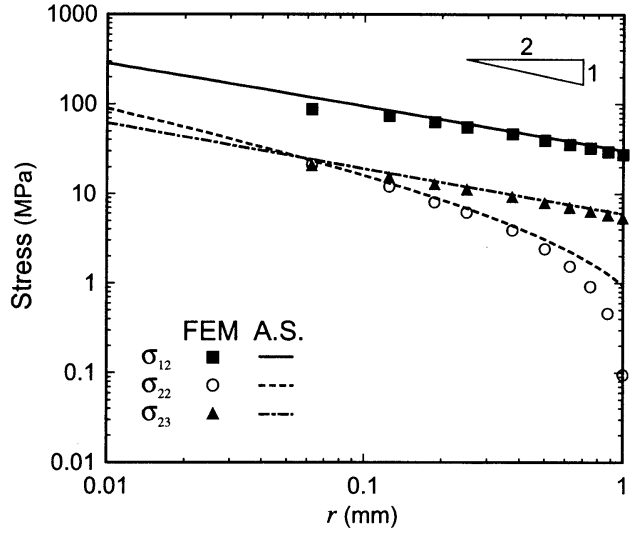

(a) $\varphi=22.5^{\circ}$

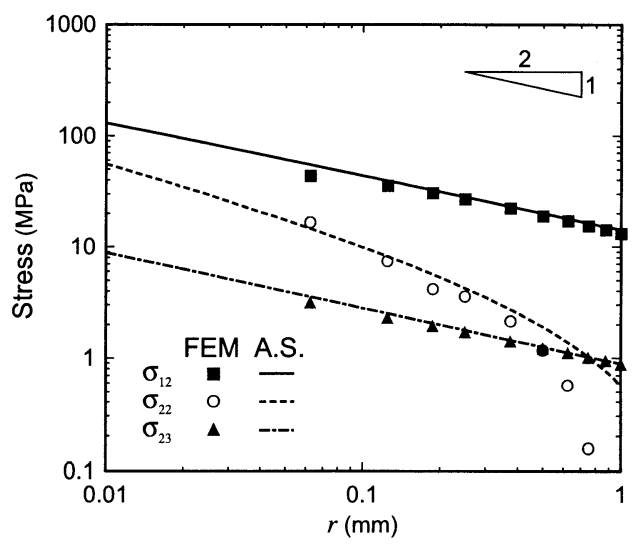

(b) $\varphi=90.0^{\circ}$

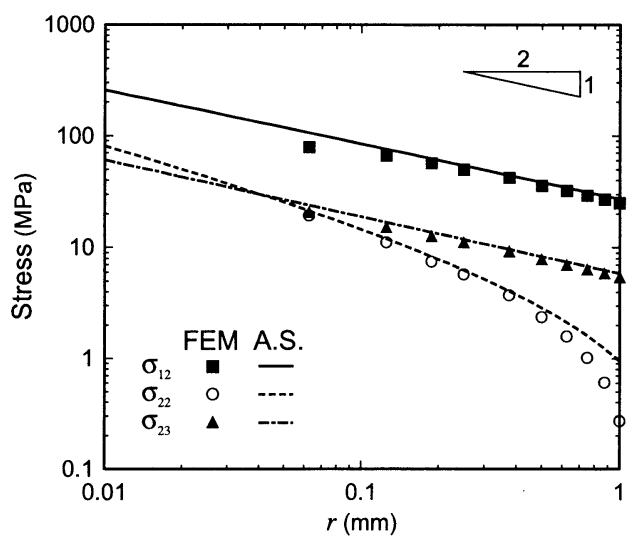

(c) $\varphi=157.5^{\circ}$

Fig. 10 Distributions of stress in the vicinity of an interface crack tip obtained by the asymptotic solution with calculated stress intensity factors and obtained by the FEM directly, for Case 1 in Sample 2 (A.S.: Asymptotic Solution). 


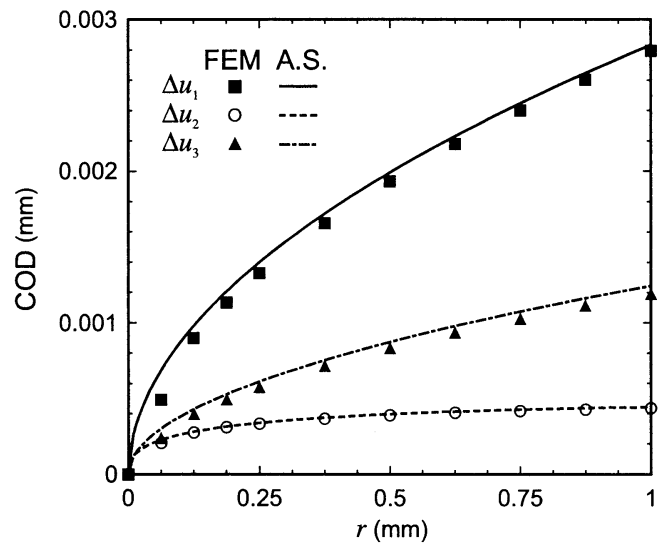

(a) $\varphi=22.5^{\circ}$

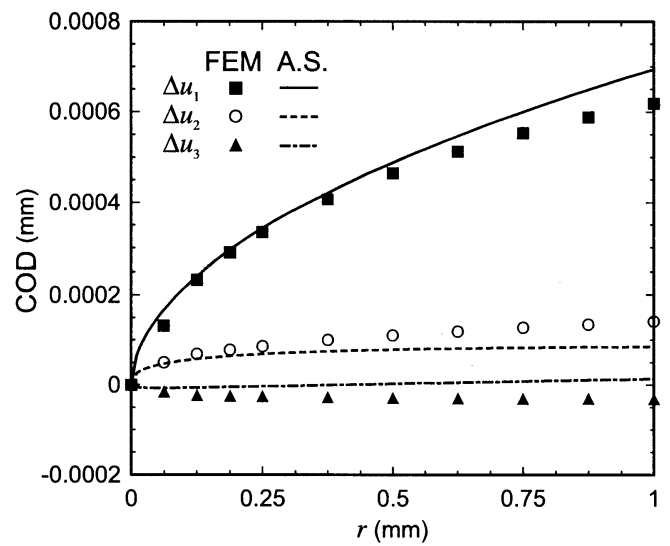

(b) $\varphi=90.0^{\circ}$

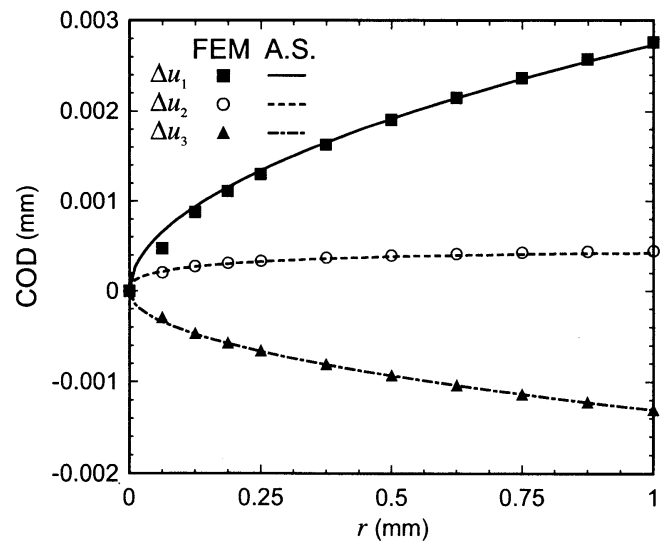

(c) $\varphi=157.5^{\circ}$

Fig. 11 Distributions of the COD in the vicinity of an interface crack tip obtained by the asymptotic solution with calculated stress intensity factors and obtained by the FEM directly, for Case 2 in Sample 1 (A.S.: Asymptotic Solution).

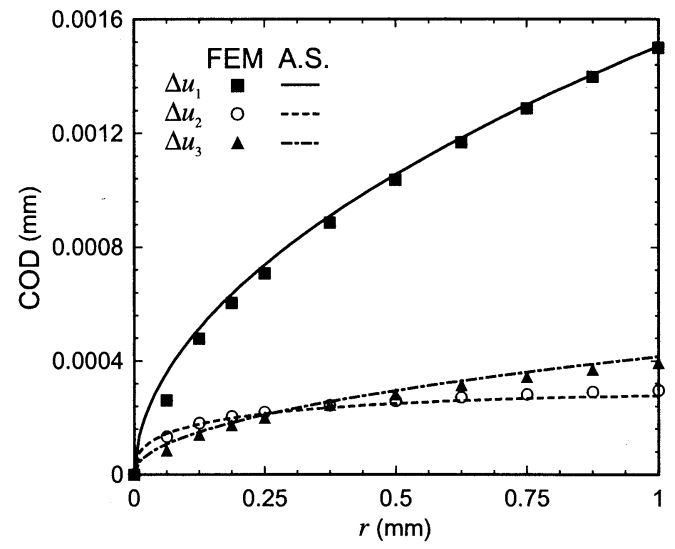

(a) $\varphi=22.5^{\circ}$

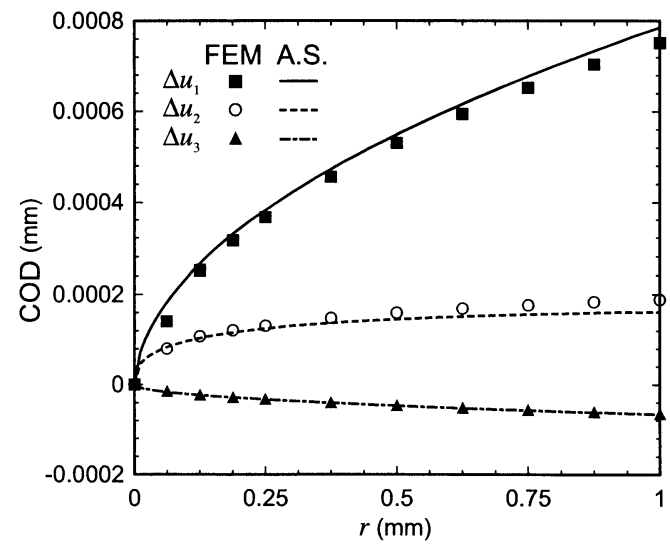

(b) $\varphi=90.0^{\circ}$

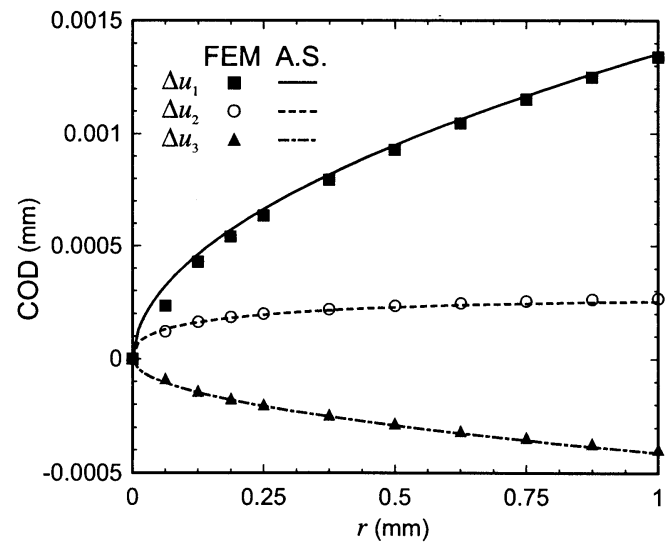

(c) $\varphi=157.5^{\circ}$

Fig. 12 Distributions of the COD in the vicinity of an interface crack tip obtained by the asymptotic solution with calculated stress intensity factors and obtained by the FEM directly, for Case 1 in Sample 2 (A.S.: Asymptotic Solution). 
め, 均質体中き裂の $r^{-12}$ 応力特異性の傾きを示してい るが, 界面き裂は, $r$ によって応力比が変化する $r^{-12+i \varepsilon}$ 特異性を示すため, その傾きも $r$ によって比を変えな がら変化する. 図9, 10 より, Case 2 の $\varphi=90^{\circ}$ での面 外せん断応力 $\sigma_{23}$ 以外は, 漸近解と有限要素法解がよ く一致しており, 本手法により得られた応力拡大係数 の值が妥当であることを示している. Case 2 の $\varphi=90^{\circ}$ での $\sigma_{23}$ に関しては，そのオーダーが非常に小さく， $r>0.1 \mathrm{~mm}$ の領域では, 特異項以外の項の影響が現れ ているため, 有限要素法解が漸近解と一致しない結果 になっている. また，図 11，12 には，き裂開口変位の $x_{1}, x_{2}, x_{3}$ 方向成分 $\Delta u_{1}, \Delta u_{2}, \Delta u_{3}$ を示した. これより, 変 位に関しても漸近解と有限要素法解がよく一致してい るのがわかる. ただし, Case 2 の $\varphi=90^{\circ}$ での結果に 関しては, 応力場の結果と同様に, 変位のオーダーが 非常に小さく, 有限要素法解に特異項以外の項の影響 が現れている.

\section{5. 結言}

熱応力下の三次元異方性異種材界面き裂の応力拡大 係数を解析する手法を開発した。この手法を, 界面に 外側円形き裂をもつ三次元接合体について，一様温度 変化と一様温度勾配を与えた問題に適用し, その解析 精度を検証した. その結果, 要素分割の精粗による解 の収束性を確認し，また漸近解と有限要素法解の応力 場・変位場が一致していることを確認した. これらの 事実より, 本手法を用いることで, 熱応力問題に関し ても応力拡大係数を精度良く求められることが確認で きた.

また, 本手法では, 移動最小自乗法と $M$ 積分を用 いることで, 汎用有限要素法コードの解析結果の節点 データだけを入力データとして簡便に解析を行うこと ができる.

本研究の一部は, 日本学術振興会科学研究費補助金 の援助により行われた. 記して感謝する.

\section{文献}

(1) Hwu, C., Fracture parameters for the orthotropic bimaterial interface cracks, Engineering Fracture Mechanics, Vol. 52 (1991), pp. 239-256.

(2) Stroh, A. N., Dislocation and cracks in anisotropic elasticity, Philosophical Magazine, Vol. 7 (1952), pp. 625-646.

(3) Qian, W. and Sun, C.T., Methods for stress intensity factors for interfacial cracks between two orthotropic solids, International Journal of Solids and Structures, Vol. 35 (1997), pp. 3317-3330.
(4) Yau, J.F. and Wang, S.S., An analysis of interface cracks between dissimilar isotropic materials using conservation integrals in elasticity, Engineering Fracture Mechanics, Vol. 20, (1984), pp. 423-432.

(5) Matos, P.P.L., McMeeking, R.M., Charalambides, P.G. and Drory, M.D., A method for calculating stress intensities in bimaterial fracture, International Journal of Fracture, Vol. 40 (1989), pp. 235-254.

(6) Yamanaga, K., Ikeda, T. and Miyazaki, N., Stress intensity factor analysis of a crack on an interface between dissimilar anisotropic materials, Transactions of the Japan Society of Mechanical Engineers, Series A, Vol. 69, No. 687 (2003), pp. 1531-1538.

(7) Nagai, M., Yamanaga, K., Ikeda, T. and Miyazaki, N., Stress intensity factor analysis of an interface crack between anisotropic dissimilar materials under thermal stress, Transactions of the Japan Society of Mechanical Engineers, Series A, Vol. 72, No. 715 (2006), pp. 285-292.

(8) Nagai, M., Ikeda, T. and Miyazak, N., Stress intensity factor analysis of an interface crack between anisotropic dissimilar materials under thermal stress, Transactions of the Japan Society of Mechanical Engineers, Series A, Vol. 72, No. 724(2006), pp. 1992-1999.

(9) Ting, T. C. T., Explicit solution and invariance of the singularities at an interface crack in anisotropic composites, International Journal of Solids and Structures, Vol. 22 (1986), pp. 965-983.

(10) Barnett, D. M. and Lothe, Synthesis of the sextic and the integral formalism for dislocations, Green's function and structure waves in anisotropic elastic solids, Physsica Norvegica, Vol. 7 (1973), pp. 13-19.

(11) Ikeda, T., Miyazaki, N., Soda, T. and Munakata, T., Mixed Mode Fracture Criteria of Interface Crack between Dissimilar Materials, Transactions of the Japan Society of Mechanical Engineers, Series A, Vol. 58, No. 555 (1992), pp. 2080-2087.

(12) Kishimoto, K., Aoki, S. and Sakata, M., On the path independent integral- $\hat{J}$, Engineering Fracture Mechanics, Vol. 13 (1980), pp. 841-850.

(13) Choy, M. M., Landolt-Börnstein Numerical Data and Functional Relationships in Science and Technology, New Series, Vol. 11, No. 53 (1979).

(14) Kurashige, K., Kurata, Y., Ishibashi, H. and Susa, K., Mechanical Properties of a $\mathrm{Gd}_{2} \mathrm{SiO}_{5}$ Single Crystal, Japanese Journal of applied physics, Vol. 36 (1997), pp. 2242-2246. 